\title{
Induction of protective immunity in swine by recombinant bamboo mosaic virus expressing foot-and-mouth disease virus epitopes Chung-Da Yang ${ }^{\dagger 1}$, Jia-Teh Liao ${ }^{\dagger 3}$, Chen-Yen Lai ${ }^{1}$, Ming-Hwa Jong ${ }^{4}$, Chi- Ming Liang5, Yeou-Liang Lin, Na-Sheng Lin*1,2, Yau-Heiu Hsu*3 and Shu- Mei Liang*1,3
}

Address: ${ }^{1}$ Agricultural Biotechnology Research Center, Academia Sinica, Taipei 11529, Taiwan, ${ }^{2}$ Institute of Plant and Microbial Biology, Academia Sinica, Taipei, Taiwan, ${ }^{3}$ Graduate Institute of Biotechnology, National Chung Hsing University, Taichung, Taiwan, ${ }^{4}$ National Institute for Animal Health, Taipei, Taiwan and ${ }^{5}$ National Health Research Institutes, Zhunan, Taiwan

Email: Chung-Da Yang - toxogondii@yahoo.com.tw; Jia-Teh Liao - jtliao@ms50.url.com.tw; Chen-Yen Lai - cylai@gate.sinica.edu.tw; MingHwa Jong - hc@mail.nvri.gov.tw; Chi-Ming Liang - cmliang@nhri.org.tw; Yeou-Liang Lin - yllin@mail.nvri.gov.tw; Na-

Sheng Lin* - nslin@sinica.edu.tw; Yau-Heiu Hsu* - yhhsu@dragon.nchu.edu.tw; Shu-Mei Liang* - smyang@gate.sinica.edu.tw

* Corresponding authors †Equal contributors

Published: 27 September 2007

BMC Biotechnology 2007, 7:62 doi:10.1 |86/1472-6750-7-62
Received: I March 2007

Accepted: 27 September 2007

This article is available from: http://www.biomedcentral.com/1472-6750/7/62

(c) 2007 Yang et al; licensee BioMed Central Ltd.

This is an Open Access article distributed under the terms of the Creative Commons Attribution License (http://creativecommons.org/licenses/by/2.0), which permits unrestricted use, distribution, and reproduction in any medium, provided the original work is properly cited.

\begin{abstract}
Background: Plant viruses can be employed as versatile vectors for the production of vaccines by expressing immunogenic epitopes on the surface of chimeric viral particles. Although several viruses, including tobacco mosaic virus, potato virus $X$ and cowpea mosaic virus, have been developed as vectors, we aimed to develop a new viral vaccine delivery system, a bamboo mosaic virus (BaMV), that would carry larger transgene loads, and generate better immunity in the target animals with fewer adverse environmental effects.
\end{abstract}

Methods: We engineered the BaMV as a vaccine vector expressing the antigenic epitope(s) of the capsid protein VPI of foot-and-mouth disease virus (FMDV). The recombinant BaMV plasmid ( $\mathrm{PBVPI}$ ) was constructed by replacing DNA encoding the $35 \mathrm{~N}$-terminal amino acid residues of the BaMV coat protein with that encoding 37 amino acid residues ( $\left.T^{128}-\mathrm{N}^{164}\right)$ of FMDV VPI.

Results: The pBVPI was able to infect host plants and to generate a chimeric virion BVPI expressing VPI epitopes in its coat protein. Inoculation of swine with BVPI virions resulted in the production of anti-FMDV neutralizing antibodies. Real-time PCR analysis of peripheral blood mononuclear cells from the BVPI-immunized swine revealed that they produced VPI-specific IFN$\gamma$. Furthermore, all BVPI-immunized swine were protected against FMDV challenge.

Conclusion: Chimeric BaMV virions that express partial sequence of FMDV VPI can effectively induce not only humoral and cell-mediated immune responses but also full protection against FMDV in target animals. This BaMV-based vector technology may be applied to other vaccines that require correct expression of antigens on chimeric viral particles. 


\section{Background}

Foot-and-mouth disease virus (FMDV) is the etiological agent of foot-and-mouth disease (FMD) that infects cloven-hoofed animals such as pigs, sheep and cattle and causes serious damage in the livestock industry [1]. Although conventional vaccines based on the chemically inactivated virus are effective against FMDV [2], outbreaks of FMD sometimes result from virus escaping from vaccine production units or from the use of improperly inactivated virus [2-4]. Alternative approaches to produce an effective and safe FMD vaccine are needed to replace inactivated virus-based vaccines.

FMDV particles are composed of 60 copies of each of four capsid proteins termed VP1, VP2, VP3 and VP4, which are cleavage products of the capsid precursor polypeptide P1[5,6]. VP1, VP2 and VP3 form the outer capsid shell, whereas VP4 lines the interior surface [7]. Among these capsid proteins, VP1 contains the major antigenic domains of the virus [8-11], with its G-H loop including at its apex a highly conserved Arg-Gly-Asp (RGD) tripeptide, which can bind to integrins and facilitate the internalization of FMDV into target cells $[12,13]$. Therefore, many investigators have used VP1 as a candidate vaccine against FMDV [10].

Chimeric plant virus-derived vaccines against FMD have been described and used in experimental or natural hosts [14-16]. Cowpea mosaic virus (CPMV) expressing VP1 epitopes on the surface of the virus was first reported to react with FMDV-specific antiserum [14]. Tobacco mosaic virus (TMV) expressing the full VP1 protein or an epitope of VP1 was subsequently shown to induce protective immunity against FMDV in both mice and swine $[15,16]$. Although preliminary protection against FMDV in swine was demonstrated with TMV expressing the VP1 epitope [16], effort is needed to improve not only the replication efficiency and stability of such chimeric viruses but also the immune responses they induce [17].

Recently, potato virus X (PVX), a member of the Potexvirus genus, was reported to be an effective epitope presentation system for chimeric virus particle production [18-21]. Analysis by fiber diffraction pattern has shown that the surface features of PVX are more flexible than those of TMV [22], which likely contributes significantly to the accommodation of foreign peptides on the surface of the virus. Bamboo mosaic virus (BaMV) is also a flexuous rodshaped member of the Potexvirus genus. It infects both monocotyledonous and dicotyledonous plants [23]. The viral genome of BaMV consists of a single-stranded positive-sense RNA molecule with a 5' cap structure and 3' poly(A) tail that contains five major open reading frames (ORFs) encoding different target proteins for viral replication, movement and assembly [24-27]. The ORF5 encodes a coat protein (CP) for virus encapsidation, cell-to-cell and long-distance movement [24].

Here we describe generation of a recombinant BaMVbased vector, namely pBVP1, by replacing complementary DNA (cDNA) encoding 35 amino acid residues from the $\mathrm{N}$-terminal sequence of BaMV CP with cDNA encoding 37 amino acid residues $\left(\mathrm{T}^{128}-\mathrm{N}^{164}\right)$ of FMDV (O/Taiwan/97) VP1. We examined the ability of this recombinant viral vector to generate a chimeric BaMV virus in plants and the effectiveness of the chimeric virus to induce immune responses and protection of swine against FMDV challenge.

\section{Methods}

Construction of an recombinant infectious PBVPI vector

The full-length infectious cDNA of BaMV-S with an upstream cauliflower mosaic virus $35 \mathrm{~S}$ promoter sequence was cloned in the plasmid pUC119 (Fig. 1a) as described previously [27]. A vector pBS-d35CP was derived from the aforementioned pBaMV-S plasmid by deletion of the $\mathrm{N}$-terminal 35 amino acid sequence of $\mathrm{CP}$ and insertion of multiple cloning sites (AgeI-NheI-NotI) by PCR (Fig. 1b). A sequence corresponding to amino acids 128-164 of VP1 of FMDV serotype O/Taiwan/97 was inserted into pBS-d35CP by PCR with the plasmid pVP1/Q15 used as a template [28]. The primers used were pr128164N (5'-GGgctagcAccatggACACCGTCTACAACGGGAG-3'; the sequence in small letters represents the sequentially ordered NheI and NcoI sites; the NcoI recognition sequence provided an AUG initiation codon) and pr128164C (5'-TTgcggccgcGTTGAAGGAGGTAGGC-3'; the sequence in small letters represents a NotI site). PCR was carried out at an initial temperature of $94^{\circ} \mathrm{C}$ for $5 \mathrm{~min}$ followed by 25 cycles of $94^{\circ} \mathrm{C}$ for $30 \mathrm{~s}, 50^{\circ} \mathrm{C}$ for $30 \mathrm{~s}$ and an extension at $72^{\circ} \mathrm{C}$ for $30 \mathrm{~s}$. The amplified fragment encoding VP1 peptide was purified, sequenced and cloned into plasmid pBS-d35CP at the NheI and NotI sites. The sequence of the new plasmid was confirmed and denoted as pBVP1 (Fig. 1c).

\section{Virus propagation and purification}

Plants of the local lesion host Chenopodium quinoa (C. quinoa) and systemic host Nicotiana benthamiana (N. benthamiana) were grown in a greenhouse exposed to normal daylight. For the infectivity assay, approximately $1 \mu \mathrm{g}$ of purified viral DNA plasmids in $10 \mu \mathrm{l}$ of double-distilled $\mathrm{H}_{2} \mathrm{O}$ was used to inoculate each leaf of test plants at the 6leaf stage [27]. Observations for local lesions took place 10 days post-inoculation. For antigen preparation, 8 to 10 fully expanded leaves of $C$. quinoa plants that had been inoculated with $\mathrm{pBaMV}-\mathrm{S}$ or $\mathrm{pBVP} 1$ were harvested at 10 days post-inoculation. The virions were subsequently purified from the leaves and the yield was determined by ultraviolet absorption as described previously [29]. The 
(a) pBaMV-S

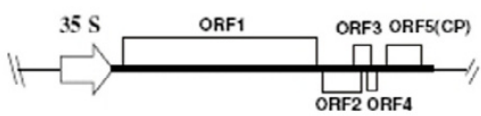

(b) pBS-d35CP

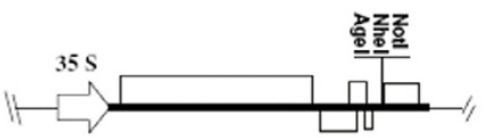

(c) pBVP1

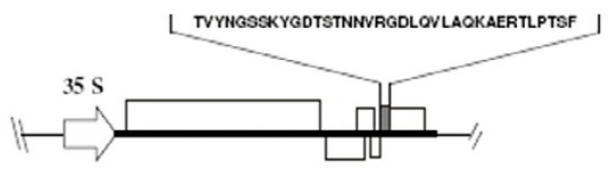

Figure I

Schematic representation of plasmids of wild-type BaMV-S as well as recombinant pBS-d35CP and pBVPI. (a) pBaMV-S is an infectious BaMV cDNA plasmid under the control of cauliflower mosaic virus $35 \mathrm{~S}$ promoter. The BaMV genome comprises 5 open reading frames (ORFs). The ORFI encodes for viral replicase, whereas ORF2, ORF3 and ORF4 are called a "Triple-gene-block" that encodes viral movement proteins. ORF5 (CP) encodes a structural protein for virion formation. (b) PBS-d35CP is a mutated $\mathrm{BaMV}$ plasmid whose DNA coding for the $\mathrm{N}$-terminal 35 amino acids of $\mathrm{CP}$ has been truncated, and multiple cloning sites have been engineered. (c) PBVPI is a recombinant plasmid derived from PBS-d35CP by inserting the DNA coding for the 37 amino acid VPI peptide to replace that coding for the $\mathrm{N}$-terminal 35 amino acids of CP.

amount of VP1 epitope expressed in the chimeric virus BVP1 was estimated at about $14.3 \%$ of the total viral coat proteins. Purified virions were dissolved in BE buffer (10 $\mathrm{mM}$ Borate, $\mathrm{pH} 9.0,1 \mathrm{mM}$ EDTA), then stored at $-20^{\circ} \mathrm{C}$ for subsequent immunization of swine.

\section{Western blotting analysis and immunogold labeling of virus particles}

Rabbit anti-FMDV VP1 serum was prepared as described previously [28]. Total proteins were prepared from mock or viral DNA plasmid-inoculated C. quinoa with use of 1:2 (w/v) extraction buffer (50 mM Tris- $\mathrm{HCl}, \mathrm{pH} 8.0,10 \mathrm{mM}$ $\mathrm{KCl}, 10 \mathrm{mM} \mathrm{MgCl}_{2}, 1 \mathrm{mM}$ EDTA, 20\% glycerol and 2\% SDS) and heated at $100^{\circ} \mathrm{C}$ for $5 \mathrm{~min}$. Protein samples were separated by $12 \%$ SDS-PAGE and electrophoretically transferred to Immobilon-P membranes (Bio-Rad) with $200 \mathrm{~mA}$ for $1 \mathrm{~h}$ at $4{ }^{\circ} \mathrm{C}$. After blocking, the proteins on the membranes were probed with anti-BaMV-S CP or antiFMDV VP1 antibodies or serum from FMDV-infected swine and then processed as described previously [27].

For immunogold labeling of virus particles, the pBaMV-S or pBVP1-inoculated leaves of C. quinoa were harvested at 10 days post-inoculation and the labeling procedures were conducted as described previously [30]. Briefly, grids were first floated on leaf extract for $5 \mathrm{~min}$ followed by diluted 1:100 anti-BaMV-S CP or anti-FMDV VP1 antibodies and then decorated by gold-labeled goat anti-rabbit IgG complexes. The grids were then stained with $2 \%$ uranyl acetate and examined under a Philips CM100 electron microscope.

\section{Analysis of the purity of BVPI virions on SDS-PAGE}

The recombinant virus BVP1 was purified from infected leaves and electrophoresed on a $12.5 \%$ polyacrylamide gel containing $1 \%$ SDS. The gel was stained with PlusOne Silver Staining Kit (Amersham Bioscience, Sweden).

\section{Immunization and viral challenge in swine}

Specific pathogen-free female or castrated male swine ( 2 months old, weighing approximately $25 \mathrm{~kg}$ ) were obtained in Taiwan. In experiment 1, two groups of three pigs each were immunized respectively by intramuscular injection into the neck muscles beside the ears with $10 \mathrm{mg}$ and $5 \mathrm{mg}$ of BVP1 virions emulsified with Montanide ISA 206 (Seppic, France) at a 1:1 ratio (v/v). In addition, two pigs were immunized with wild-type virus BaMV-S emulsified with Montanide ISA 206 and another two with sterile PBS buffer as negative control groups. All animals boosted with the same amount six weeks later. Sera were collected for analysis from the immunized animals at days $0,28,42,56$, and 70 . Four weeks after boost, all swine were challenged with $0.5 \mathrm{ml}$ of $10^{5.0} \mathrm{TCID}_{50}$ of FMDV O/ Taiwan/97 by subcutaneous injection into the right front heel bulb. The swine were monitored daily for FMD symptoms for 14 days. Signs of FMD symptoms included elevated body temperature above $40^{\circ} \mathrm{C}$ for 3 successive days, lameness, vesicular lesions on the snout, and coronary bands on the legs [28]. In experiment 2, three groups of three swine each were vaccinated with $5 \mathrm{mg}, 1 \mathrm{mg}$, and 0.5 mg BVP1 respectively and boosted at day 28 according to the same regimen. As negative controls, two pigs were immunized with wild-type virus BaMV-S and another two with sterile PBS buffer. Seven days after boost (i.e., on day $35)$, swine were injected with $0.5 \mathrm{ml}$ of $10^{5.0} \mathrm{TCID}_{50}$ of FMDV (O/Taiwan/97) as in experiment 1 . The viral chal- 
lenge experiments were carried out in high containment facilities.

\section{FMDV preparation for swine challenge}

The FMDV used in challenge experiments was produced from a homogenized mixture of vesicular fluid and epithelium of a pig infected with FMDV O/Taiwan/97. The titer of the virus was titrated in BHK-21 cells in accordance with FMD World Reference Laboratory, Pirbright, UK.

\section{ELISA for serum titer analysis}

ELISA was performed as described previously with minor modifications [31]. In brief, 96-well microtiter plates were coated with recombinant VP1 protein $(1 \mu \mathrm{g} /$ well $)$ in $0.1 \mathrm{M}$ carbonate/bicarbonate buffer, $\mathrm{pH} 9.4$, overnight at $4{ }^{\circ} \mathrm{C}$. Plates were blocked with $5 \%$ skim milk in PBS and washed three times with PBS containing 0.1\% Tween-20 (PBST). Samples of 1:50 diluted serum in serial dilution were added to wells ( $50 \mu \mathrm{l} /$ well) and incubated for $1 \mathrm{~h}$ at $37^{\circ} \mathrm{C}$. After three washings, a 1: 3000 diluted biotinylated goat anti-swine $\operatorname{IgG}$ antibody was added for $1 \mathrm{~h}$ at $37^{\circ} \mathrm{C}$. The plates were subsequently washed, and streptavidin:peroxidase (1:3000 dilution) was added. After incubation for $1 \mathrm{~h}$ at room temperature, the plates were washed again in PBST. Enzyme substrate 3, 3', 5, 5'tetramethylbenzidine (Sigma) was then added, and the colorigenic reaction was carried out at room temperature for $10 \mathrm{~min}$. Finally, an equal volume of $1 \mathrm{~N} \mathrm{H}_{2} \mathrm{SO}_{4}$ was added to stop the reaction, and the absorbance at $450 \mathrm{~nm}$ was measured by an ELISA reader. The titer was defined as the reciprocal of the dilution that resulted in an absorbance value $50 \%$ of total value obtained from subtracting maximum absorbance with background absorbance. The maximum absorbance is the absorbance at the plateau (around O.D. $=3.5-3.7$ ) of the curve obtained by plotting the optical density versus serial dilution of sera of immunized swine in a semi-logarithmical manner.

\section{Assay for anti-FMDV NAs}

The anti-FMDV NAs assays were carried out in 96 wells flat-bottomed plates using BHK-21 cells as described in the OIE manual [32]. In brief, sera from test animals were inactivated at $56^{\circ} \mathrm{C}$ for $30 \mathrm{~min}$. Two-fold serial dilution of sera were performed in duplicate and $50 \mu \mathrm{l}$ of each were added to the wells. Fifty $\mu \mathrm{l}$ of $100 \mathrm{TCID}_{50}$ of FMDV (O/ Taiwan/97) was then added to each well. The plate was vortexed for $1 \mathrm{~min}$ and incubated at $37^{\circ} \mathrm{C}$ for $90 \mathrm{~min}$. BHK-21 cell suspension $\left(1 \times 10^{5}\right.$ cells $)$ in EMEM containing $5 \%$ fetal bovine serum was subsequently added to each well and incubated for $48 \mathrm{~h}$. The cells were then observed under a microscope for the cytopathic effect (CPE) of the virus as indicated by disruption of cell monolayer and change of shape from spindle to round. Titers were expressed as the final dilution of serum present in the serum/virus mixture where $50 \%$ of wells are protected.

\section{Preparation of total RNA}

Peripheral blood mononuclear cells (PBMCs) isolated from test swine were seeded in triplicate in 6-well culture plates at $1 \times 10^{7}$ cells per well in $2 \mathrm{ml}$ of DMEM culture medium supplemented with $10 \%$ FBS and $1 \%$ penicillin and streptomycin. After overnight culture, cells were incubated with $5 \mu \mathrm{g} / \mathrm{ml}$ recombinant VP1 (rVP1), prepared as described previously [28], or $1 \mu \mathrm{g} / \mathrm{ml}$ of phytohaemagglutinin (PHA; Sigma) for $6 \mathrm{~h}$ at $37^{\circ} \mathrm{C}$ in $5 \% \mathrm{CO}_{2}$. Cells stimulated with PHA were used as positive controls. Following the incubation, cells were lysed in TRIzol ${ }^{\mathrm{TM}}$ reagent (Invitrogen), and total cellular RNA was isolated according to the manufacturer's instructions. The concentration of total cellular RNA was quantified by determination of optical density at $260 \mathrm{~nm}$. Total cellular RNA was reverse transcribed into cDNA by SuperScript III $^{\mathrm{TM}}$ reverse transcriptase (Invitrogen). The resulting cDNA was amplified by real-time PCR.

\section{Measurement of IFN- $\gamma$ production by real-time PCR}

Total IFN- $\gamma$ mRNA was measured by real-time PCR by use of a SYBR Green system in a LightCycler instrument (Roche Applied Science). Samples were assayed in a final volume of $20 \mu \mathrm{l}$ with use of the FastStart DNA Master SYBR Green I Kit (Roche), including heat-activatable Taq polymerase, plus $4 \mathrm{mM} \mathrm{MgCl}_{2}$, each primer (primer sequences were SW-IFN- $\gamma$ (F4), 5'-GCTCTGGGAAACTGAATGACTTCG; and SW-IFN- $\gamma$ (R4), 5 '- GACTTCTCTTCCGCTTTCTTAGGTTAG) at $0.5 \mu \mathrm{M}$ and $2 \mu \mathrm{l}$ of cDNA was prepared as described above. Following polymerase activation $\left(95^{\circ} \mathrm{C}\right.$ for $\left.10 \mathrm{~min}\right), 40$ cycles were run with a $15 \mathrm{~s}$ denaturation at $95^{\circ} \mathrm{C}, 2 \mathrm{~s}$ annealing at $60^{\circ} \mathrm{C}$, and $15 \mathrm{~s}$ extension at $72^{\circ} \mathrm{C}$. The temperature transition rate was $20^{\circ} \mathrm{C} / \mathrm{s}$ for all steps. The amount of PCR product was measured once every cycle immediately after the $72^{\circ} \mathrm{C}$ incubation (extension step) by detection of the fluorescence associated with the binding of SYBR Green I to the amplification product. Fluorescence curves were analyzed with use of LightCycler software, version 3.0 (RocheApplied Science). The primers were synthesized by Invitrogen Life Technologies. For each sample, the amount of IFN- $\gamma$ was determined by comparing with a standard curve and normalized by using $\beta$-actin as the internal reference. All samples were processed in triplicate.

\section{Detection of antibodies against the non-structural protein of FMDV}

Infected animals produce antibodies to both the structural and non-structural proteins of FMDV. Therefore, the presence of antibodies against only structural but not nonstructural proteins can differentiate vaccinated animals from infected ones [33]. The occurrence of FMDV infection in swine was determined by measuring elicitation of antibodies against non-structural $3 \mathrm{ABC}$ proteins. Sera from all groups of swine were collected 8 and 14 days post 
challenge. The presence of antibodies against the nonstructural protein $3 \mathrm{ABC}$ of FMDV in sera were measured with use of the Ceditest ${ }^{\oplus}$ FMDV-NS strip ELISA kit (Cedi Diagnostics BV) [33] according to the manufacturer's instructions.

\section{Results \\ Characterization of a recombinant infectious pBVPI vector}

To use a BaMV-based vector to express VP1 epitopes of FMDV, we first constructed a modified BaMV vector, pBSd35CP, derived from a pBaMV-S vector (Fig. 1a) by deleting 35 amino acids from the $\mathrm{N}$-terminal $\mathrm{CP}$ and inserting multiple cloning sites (Fig. 1b). A cDNA sequence corresponding to the FMDV (O/Taiwan/97) VP1 128-164 amino acids was then cloned into the $\mathrm{CP}$ truncated region of pBS-d35CP to generate the pBVP1 vector (Fig. 1c). We revealed the infectivity of the recombinant viral vector in both the systemic host $N$. benthamiana and the local lesion host C. quinoa. In N. benthamiana, infection with pBVP1 produced milder mosaic symptoms than that with pBaMV-S, the full-length infectious cDNA of wild-type BaMV. In C. quinoa, chlorotic local lesions formed after pBVP1 inoculation were also distinct from those caused by pBaMV-S.

\section{Detection of VPI epitopes in plants infected with pBVPI}

We then determined whether pBVP1 could infect target plants to generate BaMV CP containing VP1 epitopes of FMDV. Total protein samples taken from $C$. quinoa leaves inoculated with distilled water (mock), pBaMV-S, pBSd35CP or pBVP1 were respectively subjected to SDS-polyacrylamide gel electrophoresis (SDS-PAGE; Fig. 2A) and Western blotting analysis with use of anti-BaMV-S CP antibodies (Fig. 2B). As anticipated, protein extract of mock-inoculated leaves showed no BaMV CP (Fig. 2A and 2B, lane 1). The N-terminal truncated $\mathrm{CP}$ (Fig. 2A and 2B, lane 3 ), detected in the protein extract of pBS-d35CPinoculated plants, migrated faster than the wild-type $\mathrm{CP}$ of pBaMV-S-infected plants (Fig. 2A and 2B, lane 2), which in turns migrated slightly faster than the chimeric CP from pBVP1 inoculated plants (Fig. 2A and 2B, lane 4). These results indicate an apparent size difference between the CP generated from pBVP1 and those from pBaMV-S and pBS-d35CP.

To further verify that CP generated from pBVP1-inoculated plants contained the VP1 antigenic epitopes of FMDV, Western blotting analysis with use of rabbit serum against FMDV VP1 (Fig. 2C) or serum from FMDVinfected swine (Fig. 2D) was undertaken. Both sera recognized a protein band of $31 \mathrm{kDa}$ corresponding to the chimeric CP (Fig. 2C and 2D, lane 4). In contrast, no protein band was detected in the wild-type CP of BaMV-S (Fig. 2C and 2D, lane 2) or truncated CP of BS-d35CP (Fig. 2C and

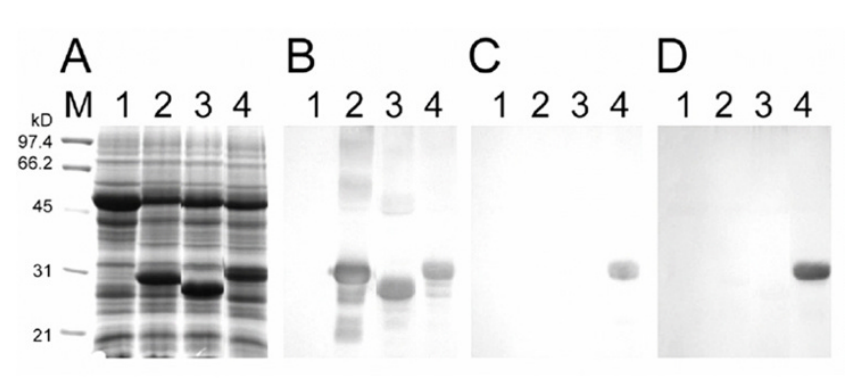

Figure 2

Detection of VPI antigenic epitopes in Chenopodium quinoa (C. quinoa) leaves inoculated with chimeric virus BVP I. Leaves of $C$. quinoa were mock-inoculated (lane I) or inoculated with wild-type pBaMV-S (lane 2), pBS-d35CP (lane 3) or PBVPI (lane 4). Total proteins were prepared as described in Methods and electrophoretically separated on a I $2 \%$ SDS-polyacrylamide gel, stained with Coomassie blue (panel A), or transferred to PVDF membrane, and detected with anti-BaMV-S CP serum (panel B), rabbit anti-FMDV VPI serum (panel C), or serum from FMDV-infected swine (panel D).

2D, lane 3). Additional immunoblotting studies with the same antibodies in C. quinoa showed that even after five subsequent passages, protein extracts of pBVP1-inoculated leaves still contained a major protein band with similar mobility to chimeric CP (data not shown). Taken together, these results suggest that the inoculation of plants with pBVP1 plasmid generates a fusion protein comprised of truncated CP of BaMV and the VP1 epitopes of FMDV.

\section{Expression of FMDV VPI epitopes on BVPI virus particles} To further confirm that the FMDV VP1 epitopes was expressed on the viral surface, the chimeric virus, namely BVP1, was isolated from pBVP1-infected C. quinoa leaf tissue. The yield of the purified virus was estimated to be around $0.2-0.5 \mathrm{mg}$ per gram of fresh leaf tissue. The purified BVP1 virus was analyzed by gel electrophoresis and silver staining. As shown in Fig. 3, small amounts of virus samples ( $5 \mathrm{ng}$ and $50 \mathrm{ng}$ ) showed only single major band. When larger amount of virions (500 ng) was loaded, the majority of proteins migrated as $31 \mathrm{kD}$ of chimeric $\mathrm{CP}$ while several low molecular weight bands of degraded CP were detected. The presence of the FMDV VP1 peptide on the virus surface was subsequently determined by using anti-BaMV CP or anti-FMDV VP1 antibodies, and the formation of the antibody-antigen complexes was detected with use of gold-labeled secondary antibodies and immunoelectron microscopy. We found that chimeric BVP1 virions were specifically labeled with anti-BaMV CP and antiFMDV VP1 respectively (Fig. 4A and 4B). In contrast, BaMV-S virions were merely labeled with anti-BaMV CP serum (data not shown) but not with anti-FMDV VP1 


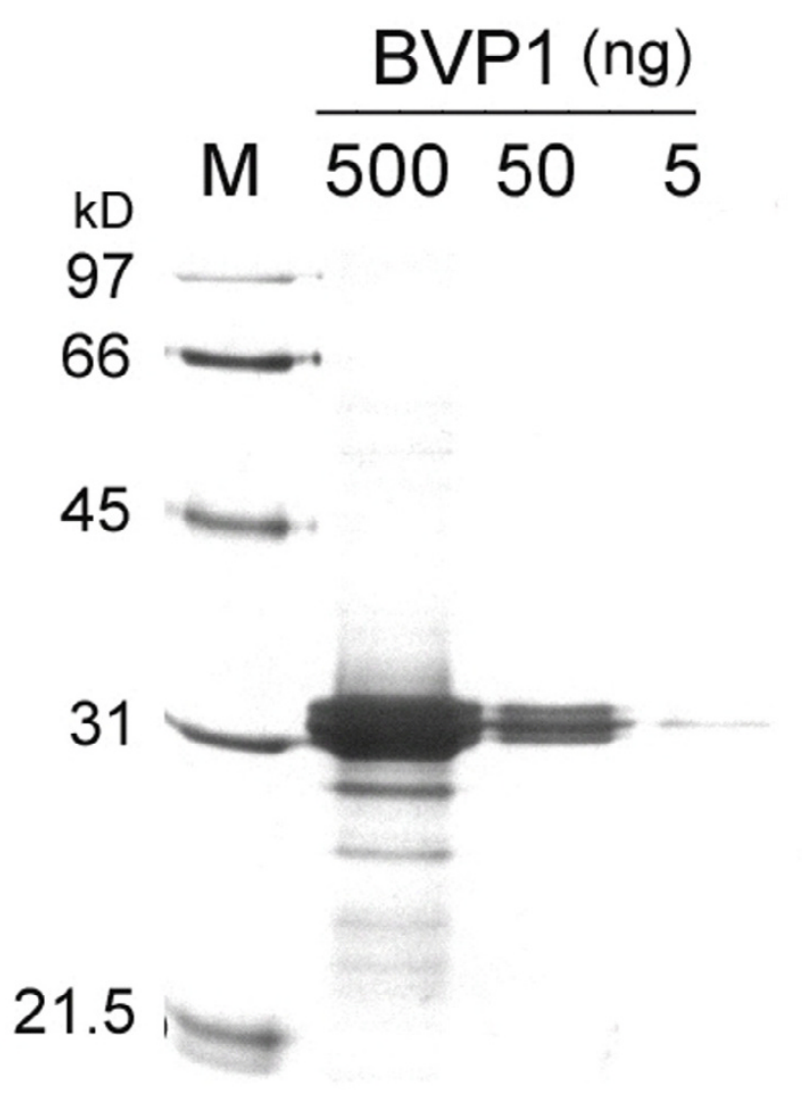

Figure 3

Analysis of purified BVP I virions on SDS- PAGE. Various amounts of BVPI virions purified from infected leaves by $\mathrm{CsCl}_{2}$ density gradient centrifugation were analyzed by electrophoresis through a $12.5 \%$ polyacrylamide and stained with PlusOne Silver Staining Kit (Amersham Bioscience, Sweden). Lane $M$, molecular weight standards. The relative molecular weights were as indicated on the left.

(Fig. 4C). By negatively staining, no difference in morphology could be observed between wild type BaMV and chimeric virus BVP1. These data indicate that the FMDV VP1 peptide is fused to BaMV CP and expressed on the viral surface.

\section{Antibody responses elicited by chimeric virus BVPI in swine} We then evaluated the ability of this chimeric virus to trigger immunity against FMDV in swine. In our first experiment, two groups of three pigs each were given intramuscular injections of $5 \mathrm{mg}$ and $10 \mathrm{mg}$ of BVP1 chimeric virus respectively and boosted with similar amount of BVP1 6 weeks later. Another two groups of two pigs each were vaccinated with $5 \mathrm{mg}$ BaMV-S wild-type virus or PBS buffer respectively as negative controls. Sera obtained from both $5 \mathrm{mg}$ and $10 \mathrm{mg}$ BVP1-immunized swine elicited high levels of anti-VP1 antibodies, as measured by ELISA. In contrast, swine immunized with BaMV-S or PBS buffer all showed little, if any, anti-VP1 antibodies (Fig. 5). Furthermore, neutralizing antibodies (NAs) were detected in the sera of the BVP1-vaccinated groups but not in those of the negative control groups (Table 1). To confirm that even smaller amounts of BVP1 could exhibit similar effects, we immunized swine with either $0.5 \mathrm{mg}$ or $1 \mathrm{mg}$ of BVP1 and boosted with similar amounts of BVP1 4 weeks later. Substantial titers of anti-VP1 antibodies (Fig. 5) and NAs (Table 1) were detected even in the sera of swine given one inoculation of $0.5 \mathrm{mg} \mathrm{BVP1}$, indicating that the chimeric BVP1 virus can effectively trigger specific NAs in swine.

\section{IF $\mathbf{N}-\gamma$ production in immunized swine}

To evaluate whether BVP1-immunized swine could induce a cell-mediated immune response in addition to NAs (a humoral response), we analyzed the ability of PBMCs to produce IFN- $\gamma$, a cytokine that plays an important role in cell-mediated immune responses. Real-time PCR analysis of specific IFN- $\gamma$ mRNA showed that upon VP1 antigen stimulation, PBMCs from BVP1-immunized swine induced production of IFN- $\gamma$ whereas BaMV-S or PBS-immunized swine did not (Table 2). As control, PBMCs from all groups of swine were stimulated with $\mathrm{T}$ cell mitogen PHA $(1 \mu \mathrm{g} / \mathrm{ml})$ and found to produce similar amounts of IFN- $\gamma$ (Table 2).

\section{Protection against FMDV challenge in immunized swine}

We then determined whether BVP1 could confer immunoprotection in swine. All groups of swine were challenged with $10^{5.0}$ TCID $_{50}$ (50\% tissue culture infective dose) of FMDV (O/Taiwan/97) and monitored for the appearance of FMD symptoms for two weeks. At days 2-4 after challenge, the negative control groups showed serious symptoms of FMD. In contrast, all swine immunized with BVP1 showed no FMD symptoms after challenge. In addition, since infected animals produce antibodies to both the structural and non-structural proteins of FMDV, the presence of antibodies against only structural but not non-structural proteins can differentiate vaccinated animals from infected ones [33]. We thus examined the presence of FMDV in sera of all animals 8-14 days after FMDV challenge by measuring antibodies against non-structural protein 3ABC. All the groups immunized with BVP1 did not develop an antibody response to $3 \mathrm{ABC}$ while control groups became 3ABC positive (Table 3 ).

\section{Discussion}

Although use of CPMV and TMV as a vector to generate chimeric plant virus-derived vaccines against FMD has been described [14-16], effort is needed to improve not only the stability of such chimeric viruses but also the immune responses and protection they induce in the target animals [17]. Recently developed was a modified TMV-based vector that allows for the expression of pep- 

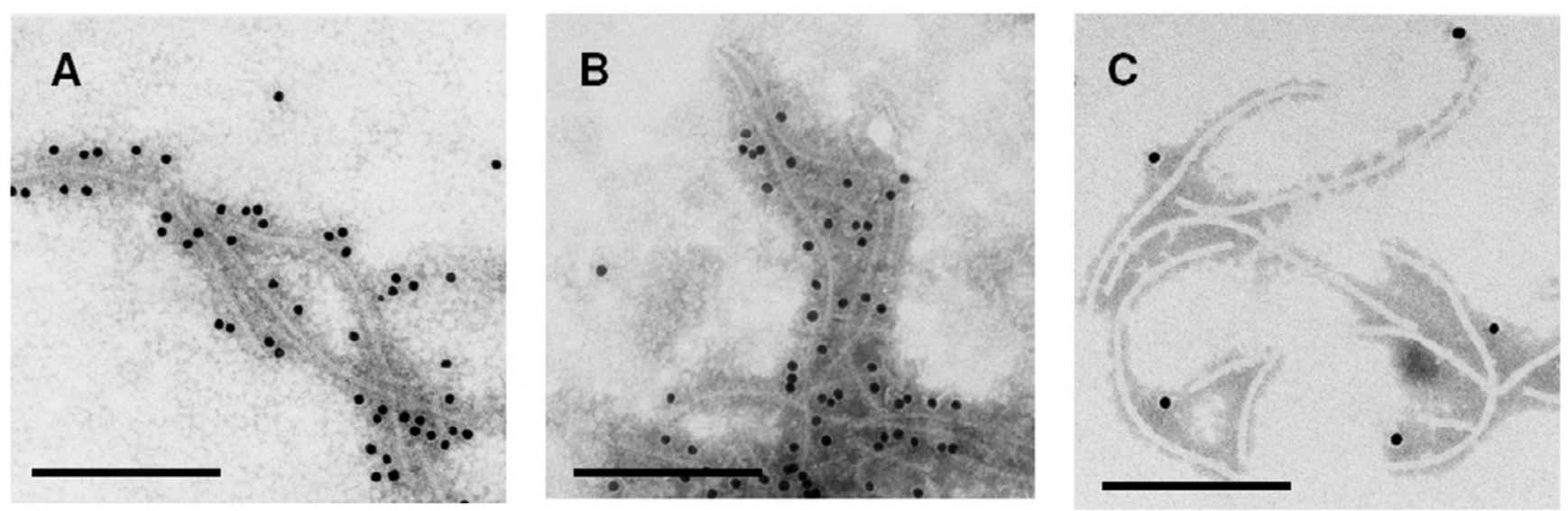

\section{Figure 4}

Immunoelectron microscopy for identification of BaMV CP and FMDV VPI on the surface of virus particles. Leaf dips from $C$. quinoa infected with pBVPI (A, B) or pBaMV-S (C) were obtained I0 days post-inoculation. Grids were first incubated with leaf extract and coated with diluted anti-BaMV CP serum $(A)$ or anti-FMDV VPI serum (B, C) followed by goldlabeled goat anti-rabbit IgG complexes. Grids were inspected in a Philips CMI00 electron microscope. All bars represent 250 $\mathrm{nm}$.

tides as long as 25 amino acids. Such chimeric constructs, however, are not as effective as the TMV expressing the 11 amino acid epitope in generating protective immunity [34]. In this study, we infected plants with plasmid pBVP1 to generate a chimeric virion (BVP1) expressing a 37 amino acid peptide of VP1 and elicited strong immunity in swine even after just one inoculation (Table 1 and Fig. $5)$. The BaMV-based expression system therefore may be better than the TMV system in expressing peptides up to 37 amino acids or longer. However, as different transgenes were used in BaMV, CPMV and TMV, it is difficult to judge at present whether chimeric BaMV is better than chimeric CPMV and TMV in terms of their elicitation of immune responses.

The prominent G-H loop of the capsid protein VP1 of FMDV, including at its apex a highly conserved Arg-GlyAsp (RGD) tripeptide, has been identified as a major Bcell epitope for eliciting NAs [8-11]. However, administering G-H loop synthetic peptides alone in cattle and swine has resulted in limited induction of NAs or ineffective protection [35]. Piatti and others [36] showed induction of both T-cell immunity and high NA response positively correlated with effective protection in experimental animals immunized with inactivated FMDV. Parida and coauthors [37] have thus suggested that evaluation of effective protection of FMD vaccine should combine the presence of NAs and IFN- $\gamma$ production (an indicator of cell-mediated immunity). Because the VP1 sequence (residues 135-160) of FMDV O1 Campos contains not only the G-H loop, the major B-cell epitope, but also the immunodominant $\mathrm{T}$ epitopes [38-40], in this study, we introduced residues 128-164, which includes $\mathrm{T}$ and $\mathrm{B}$ epitopes, of the VP1 sequence into the BaMV-based vector. Swine immunized with BVP1 elicited VP1-specific IFN- $\gamma$ and high titers of NA against FMDV (Tables 1 and 2 ). To our knowledge, this is the first report of a chimeric plant virus correctly expressing VP1 epitope(s) to properly induce both humoral (as indicated by NAs) and cellmediated immune responses (as indicated by VP1-specific IFN- $\gamma$ production).

Most importantly, our results have clearly demonstrated that BVP1 immunization can protect swine against a challenge of $10^{5.0} \mathrm{TCID}_{50} \mathrm{FMDV}$, an amount 10 times higher than that recommended by the World Organization for Animal Health [32]. In addition, we have recently examined whether one inoculation is sufficient to protect the animals. Our preliminary results revealed that swine immunized once with $1 \mathrm{mg}$ BVP1 were protected from FMDV challenge. We thus propose that BVP1 may be superior to other plant viruses such as TMV in presenting the VP1 peptide so that the immunogenic site(s) of the peptide mimic the conformation of the major antigenic epitope(s) of FMDV, thereby generating high titers of NAs as well as cellular immune responses. More studies involving the incorporation of the similar transgene into TMV and evaluation of the optimal dosage for protection, however, must be undertaken to confirm this proposal. Of note, an important advantage of the BaMV-based vector 
Table I: Titers of neutralizing antibodies (NAs) in swine immunized with chimeric virus BVP I

\begin{tabular}{|c|c|c|c|c|}
\hline \multirow[b]{3}{*}{ Antigens } & \multirow[b]{3}{*}{ Swine No. } & \multicolumn{3}{|c|}{ Experiment I } \\
\hline & & \multicolumn{3}{|c|}{ NA titers ${ }^{a}$} \\
\hline & & $4 W$ & $6 \mathrm{~W}$ & IOW \\
\hline \multirow[t]{3}{*}{$10 \mathrm{mg}$ BVPI } & 858 & 8 & 64 & 11 \\
\hline & 859 & II & 362 & 362 \\
\hline & 860 & 16 & 256 & 256 \\
\hline \multirow[t]{3}{*}{5 mg BVPI } & 861 & 6 & 32 & 23 \\
\hline & 862 & 91 & 362 & 512 \\
\hline & 863 & 64 & 256 & 256 \\
\hline \multirow[t]{2}{*}{$5 \mathrm{mg}$ BaMV-S } & 864 & - & - & - \\
\hline & 865 & - & - & - \\
\hline \multirow[t]{2}{*}{ PBS } & 866 & - & - & - \\
\hline & 867 & - & - & - \\
\hline
\end{tabular}

Experiment 2

\begin{tabular}{|c|c|c|c|c|}
\hline \multirow[b]{2}{*}{ Antigens } & \multirow[b]{2}{*}{ Swine No. } & \multicolumn{3}{|c|}{ NA titers ${ }^{a}$} \\
\hline & & $3 \mathrm{~W}$ & $4 \mathrm{~W}$ & $5 W$ \\
\hline \multirow[t]{3}{*}{5 mg BVPI } & $\mathrm{I}$ & 4 & 8 & 11 \\
\hline & 2 & 32 & 128 & 128 \\
\hline & 3 & 16 & 64 & 45 \\
\hline \multirow[t]{3}{*}{ I mg BVPI } & 4 & 16 & 32 & 256 \\
\hline & 5 & 4 & 16 & 23 \\
\hline & 6 & 32 & 32 & 32 \\
\hline \multirow[t]{3}{*}{$0.5 \mathrm{mg}$ BVPI } & 7 & 8 & 64 & 91 \\
\hline & 8 & - & 8 & 32 \\
\hline & 9 & 8 & 16 & 181 \\
\hline \multirow[t]{2}{*}{$5 \mathrm{mg}$ BaMV-S } & 10 & - & - & - \\
\hline & 11 & - & - & - \\
\hline \multirow[t]{2}{*}{ PBS } & 12 & - & - & - \\
\hline & 13 & - & - & - \\
\hline
\end{tabular}

a The titer of NAs from each swine was measured at indicated weeks as described in Methods. (-) means that no NAs were detected at the highest concentration tested.

over CPMV, TMV and most other plant virus-based vectors is that $\mathrm{BaMV}$ is not a pathogen for a variety of crops and therefore may be ecologically safer for field use [23].

\section{Conclusion}

We have inserted a transgene encoding a partial sequence of the capsid VP1 of FMDV in the plant virus BaMV. The recombinant plasmid could infect host plants to generate chimeric virions that elicit significant NA titers in the animals even after just one inoculation. The capability of this
BaMV-based vector to carry larger transgenes, effectively express foreign peptide epitope(s) and induce protective humoral and cellular immune responses would be advantageous for its application in the development of vaccines against not only FMDV but also many other pathogens.

\section{Competing interests}

As the content described in this paper has commercial potential, patent applications are being processed. 


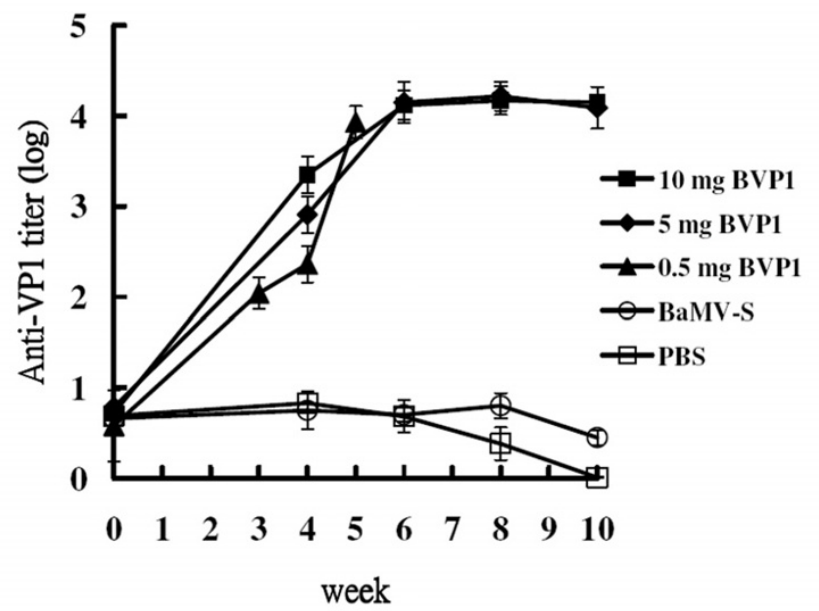

Figure 5

Serum titers of swine immunized with chimeric virus BVP I. Groups of swine were immunized with $0.5 \mathrm{mg}(\mathbf{A}), 5$ $\mathrm{mg}(\diamond), 10 \mathrm{mg}(\boldsymbol{\square})$ of chimeric virus BVPI or $5 \mathrm{mg}$ of wildtype virus BaMV-S $(\bigcirc)$ or PBS $(\square)$. Swine sera were collected at the indicated time after immunization. Anti-VPI titers were determined by ELISA. The animals inoculated with 0.5 mg BVPI were boosted with the same amount of BVPI four weeks after priming while those inoculated with $5 \mathrm{mg}$ and 10 $\mathrm{mg}$ of BVPI were boosted six weeks after priming.

\section{Authors' contributions}

CDY carried out the vaccine formulation, analyzed immune responses, and drafted the manuscript. CYL set up real-time PCR for IFN- $\gamma$ analysis. JTL, YHH and NSL constructed BaMV-based vectors, purified chimeric BVP1 and performed immunoelectron microscopy. MHJ and YLL participated in swine immunization and challenge. CML and SML designed and coordinated the study and wrote the manuscript. All authors read and approved the final manuscript.

\section{Acknowledgements}

The authors wish to thank Dr. Harry Wilson for editing the manuscript. This work was supported by grant COA 93-AS-4.2.I-ST-al to YHH from Council of Agriculture, grant NSC 92-2321-B-001-005 to NSL from National Science Council, and grant 95S-100I to SML from Academia Sinica.

Table 2: IFN- $\gamma$ production and protection in swine immunized with chimeric virus BVPI

\begin{tabular}{|c|c|c|c|c|}
\hline \multirow[b]{2}{*}{ Antigens } & \multirow[b]{2}{*}{ Swine No. } & \multicolumn{2}{|c|}{ IFN- $\gamma$ (fold change) ${ }^{\mathrm{a}}$} & \multirow[b]{2}{*}{ Clinical symptoms } \\
\hline & & rVPI & PHA & \\
\hline \multirow[t]{3}{*}{$10 \mathrm{mg}$ BVPI } & 858 & 3.8 & 2.4 & No \\
\hline & 859 & 4.1 & 2.8 & No \\
\hline & 860 & 3.4 & 2.2 & No \\
\hline \multirow[t]{3}{*}{$5 \mathrm{mg}$ BVPI } & 861 & 3.1 & 2.9 & No \\
\hline & 862 & 3.8 & 2.1 & No \\
\hline & 863 & 2.4 & 2.6 & No \\
\hline \multirow[t]{2}{*}{$5 \mathrm{mg} \mathrm{BaMV}-\mathrm{S}$} & 864 & 1.0 & 2.5 & Yes \\
\hline & 865 & I.I & 2.2 & Yes \\
\hline \multirow[t]{2}{*}{ PBS } & 866 & 1.0 & 2.6 & Yes \\
\hline & 867 & 1.0 & 2.4 & Yes \\
\hline
\end{tabular}

a PBMCs isolated from swine 10 weeks after priming were stimulated with $5 \mu \mathrm{g} / \mathrm{ml}$ of rVPI or I $\mu \mathrm{g} / \mathrm{ml}$ of PHA for $6 \mathrm{~h}$ at $37^{\circ} \mathrm{C}$. Total cellular RNA was then extracted for the assay of IFN- $\gamma$ production by real-time PCR. The fold change was determined by dividing the quantity of specific IFN- $\gamma$ mRNA from stimulated cells by the quantity of IFN- $\gamma$ mRNA from the unstimulated cells.

b Swine of all groups were challenged with FMDV (O/Taiwan/97) and monitored daily for clinical symptoms of FMD for 14 days as described in Methods. 
Table 3: Detection of anti-3ABC antibodies and clinical symptoms in swine after FMDV challenge

\begin{tabular}{|c|c|c|c|}
\hline Antigens & Swine No. & Anti-3ABCa & Clinical symptoms \\
\hline \multirow[t]{3}{*}{$5 \mathrm{mg}$ BVPI } & 1 & - & No \\
\hline & 2 & - & No \\
\hline & 3 & - & No \\
\hline \multirow[t]{3}{*}{ I mg BVPI } & 4 & - & No \\
\hline & 5 & - & No \\
\hline & 6 & - & No \\
\hline \multirow[t]{3}{*}{$0.5 \mathrm{mg}$ BVPI } & 7 & - & No \\
\hline & 8 & - & No \\
\hline & 9 & - & No \\
\hline \multirow[t]{2}{*}{ BaMV-S } & 10 & + & Yes \\
\hline & 11 & + & Yes \\
\hline \multirow[t]{2}{*}{ PBS } & 12 & + & Yes \\
\hline & 13 & + & Yes \\
\hline
\end{tabular}

a The presence of antibodies against 3ABC of FMDV were measured 8 and 14 days post challenge, respectively. $(+)$ indicates the presence of antibodies against $3 A B C$ protein. (-) indicates no antibodies against the $3 A B C$ protein.

\section{References}

I. Woolhouse M, Chase-Topping M, Haydon D, Friar J, Matthews L, Hughes G, Shaw D, Wilesmith J, Donaldson A, Cornell S, Keeling M, Grenfell B: Epidemiology. Foot-and-mouth disease under control in the UK. Nature 200I, 4 I I (6835):258-259.

2. Barteling SJ, Vreeswijk J: Developments in foot-and-mouth disease vaccines. Vaccine 199|, 9(2):75-88.

3. Brown F: New approaches to vaccination against foot-andmouth disease. Vaccine 1992, I0(14): 1022-1026.

4. Doel TR: FMD vaccines. Virus Res 2003, 9 I(I):8I-99.

5. Belsham GJ: Distinctive features of foot-and-mouth disease virus, a member of the picornavirus family; aspects of virus protein synthesis, protein processing and structure. Prog Biophys Mol Biol 1993, 60(3):24I-260.

6. Saiz M, Nunez Jl, Jimenez-Clavero MA, Baranowski E, Sobrino F: Foot-and-mouth disease virus: biology and prospects for disease control. Microbes Infect 2002, 4(I I): I I83-II92.

7. Domingo E, Baranowski E, Escarmis C, Sobrino F: Foot-and-mouth disease virus. Comp Immunol Microbiol Infect Dis 2002, 25(56):297-308.

8. Volpina OM, Surovoy AY, Zhmak MN, Kuprianova MA, Koroev DO Chepurkin AV, Toloknov AS, Ivanov VT: A peptide construct containing B-cell and T-cell epitopes from the foot-and-mouth disease viral VPI protein induces efficient antiviral protection. Vaccine 1999, I7(6):577-584.

9. Wang CY, Chang TY, Walfield AM, Ye J, Shen M, Chen SP, Li MC, Lin YL, Jong MH, Yang PC, Chyr N, Kramer E, Brown F: Effective synthetic peptide vaccine for foot-and-mouth disease in swine. Vaccine 2002,20(19-20):2603-26I0.

10. Grubman MJ, Baxt B: Foot-and-mouth disease. Clin Microbiol Rev 2004, I7(2):465-493.

II. Oliveira E, Jimenez-Clavero MA, Nunez JI, Sobrino F, Andreu D: Analysis of the immune response against mixotope peptide libraries from a main antigenic site of foot-and-mouth disease virus. Vaccine 2005, 23(20):2647-2657.

12. Baxt B, Morgan DO, Robertson BH, Timpone CA: Epitopes on foot-and-mouth disease virus outer capsid protein VPI involved in neutralization and cell attachment. J Virol 1984, 5 I (2):298-305.

13. Peng JM, Liang SM, Liang CM: VPI of foot-and-mouth disease virus induces apoptosis via the Akt signaling pathway. J Biol Chem 2004, 279(50):52168-52174.
14. Usha R, Rohll JB, Spall VE, Shanks M, Maule AJ, Johnson JE, Lomonossoff GP: Expression of an animal virus antigenic site on the surface of a plant virus particle. Virology 1993, 197(I):366-374.

15. Wigdorovitz A, Perez Filgueira DM, Robertson N, Carrillo C, Sadir AM, Morris T], Borca MV: Protection of mice against challenge with foot and mouth disease virus (FMDV) by immunization with foliar extracts from plants infected with recombinant tobacco mosaic virus expressing the FMDV structural protein VPI. Virology 1999, 264(I):85-9I.

16. Wu L, Jiang L, Zhou Z, Fan J, Zhang Q, Zhu H, Han Q, Xu Z: Expression of foot-and-mouth disease virus epitopes in tobacco by a tobacco mosaic virus-based vector. Vaccine 2003, 21 (27. 30): $4390-4398$

17. Ahlquist P, Schwartz M, Chen J, Kushner D, Hao L, Dye BT: Viral and host determinants of RNA virus vector replication and expression. Vaccine 2005, 23(I 5): I784-I787.

18. Brennan FR, Jones TD, Longstaff M, Chapman S, Bellaby T, Smith H, Xu F, Hamilton WD, Flock Jl: Immunogenicity of peptides derived from a fibronectin-binding protein of $S$. aureus expressed on two different plant viruses. Vaccine 1999, I7(1516): | $846-1857$

19. Marusic C, Rizza P, Lattanzi L, Mancini C, Spada M, Belardelli F, Benvenuto $E$, Capone I: Chimeric plant virus particles as immunogens for inducing murine and human immune responses against human immunodeficiency virus type I. J Virol 200I, 75(18):8434-8439.

20. Uhde K, Fischer R, Commandeur U: Expression of multiple foreign epitopes presented as synthetic antigens on the surface of Potato virus X particles. Arch Virol 2005, I 50(2):327-340.

21. Marconi G, Albertini E, Barone P, De Marchis F, Lico C, Marusic C Rutili D, Veronesi F, Porceddu A: In planta production of two peptides of the Classical Swine Fever Virus (CSFV) E2 glycoprotein fused to the coat protein of potato virus $X$. BMC Biotechnol 2006, 6:29.

22. Parker $L$, Kendall A, Stubbs G: Surface features of potato virus $\mathbf{X}$ from fiber diffraction. Virology 2002, 300(2):29|-295.

23. Hsu YH, Lin NS: Bamboo mosaic. In Viruses and Virus Disease of Poaceae, Gramineae Edited by: Lapierre H, Signoret PA. Paris ; 2004:723-724

24. Lin NS, Lin BY, Lo NW, Hu CC, Chow TY, Hsu YH: Nucleotide sequence of the genomic RNA of bamboo mosaic potexvirus. J Gen Virol 1994, 75 ( Pt 9):25।3-25 I8.

25. Yang CC, Liu JS, Lin CP, S. LN: Nucleotide sequence and phylogenetic analysis of a bamboo mosaic potexvirus isolate from 
common bamboo (Bambusa vulgaris McClure). Bot Bull Acad Sin 1997, 38:77-84.

26. $\mathrm{Li} \mathrm{Yl,} \mathrm{Cheng} \mathrm{YM,} \mathrm{Huang} \mathrm{YL,} \mathrm{Tsai} \mathrm{CH,} \mathrm{Hsu} \mathrm{YH,} \mathrm{Meng} \mathrm{M:} \mathrm{Identifica-}$ tion and characterization of the Escherichia coli-expressed RNA-dependent RNA polymerase of bamboo mosaic virus. J Virol 1998, 72(1 2): 10093-10099.

27. Lin MK, Chang BY, Liao JT, Lin NS, Hsu YH: Arg-16 and Arg-2I in the $\mathrm{N}$-terminal region of the triple-gene-block protein I of Bamboo mosaic virus are essential for virus movement. J Gen Virol 2004, 85(Pt I):25I-259.

28. Wang JH, Liang CM, Peng JM, Shieh JJ, Jong MH, Lin YL, Sieber M, Liang SM: Induction of immunity in swine by purified recombinant VPI of foot-and-mouth disease virus. Vaccine 2003, 2I(25-26):372I-3729.

29. Lin NS, Chen CC: Association of bamboo mosaic virus (BaMV) and $\mathrm{BaMV}$-specific electron-dense crystalline bodies with chloroplasts. Phytopathology 1991, 81: I55 I-I555.

30. Lin NS: Gold-IgG complexes improve the detection and identification of viruses in leaf dip preparations. J Virol Methods 1984, 8(3): $181-190$

31. Shieh JJ, Liang CM, Chen CY, Lee F, Jong MH, Lai SS, Liang SM: Enhancement of the immunity to foot-and-mouth disease virus by DNA priming and protein boosting immunization. Vaccine 200I, 1 9(28-29):4002-40I0.

32. OIE, Foot and mouth disease, in: Manual of Standards for Diagnostic Tests and Vaccines 2000, CHAPTER 2.I.I. 2002 [http://www.oie.int/eng/normes/mmanual/a 00024.htm].

33. Sorensen KJ, Madsen KG, Madsen ES, Salt JS, Nqindi J, Mackay DK: Differentiation of infection from vaccination in foot-andmouth disease by the detection of antibodies to the nonstructural proteins 3D, 3AB and 3ABC in ELISA using antigens expressed in baculovirus. Arch Virol 1998, 143(8): | $46 \mid-1476$.

34. Jiang L, Li Q, Li M, Zhou Z, Wu L, Fan J, Zhang Q, Zhu H, Xu Z: A modified TMV-based vector facilitates the expression of longer foreign epitopes in tobacco. Vaccine 2006, 24(2): $109-115$.

35. Meloen RH, Casal JI, Dalsgaard K, Langeveld JP: Synthetic peptide vaccines: success at last. Vaccine 1995, I 3(1 0):885-886.

36. Piatti PG, Berinstein A, Lopez OJ, Borca MV, Fernandez F, Schudel AA, Sadir AM: Comparison of the immune response elicited by infectious and inactivated foot-and-mouth disease virus in mice. J Gen Virol 199I, 72 ( Pt 7): |69|-1694.

37. Parida S, Oh Y, Reid SM, Cox SJ, Statham RJ, Mahapatra M, Anderson J, Barnett PV, Charleston B, Paton DJ: Interferon-gamma production in vitro from whole blood of foot-and-mouth disease virus (FMDV) vaccinated and infected cattle after incubation with inactivated FMDV. Vaccine 2006, 24(7):964-969.

38. Zamorano P, Wigdorovitz A, Chaher MT, Fernandez FM, Carrillo $C$, Marcovecchio FE, Sadir AM, Borca MV: Recognition of B and T cell epitopes by cattle immunized with a synthetic peptide containing the major immunogenic site of VPI FMDV 0 I Campos. Virology 1994, 20 I(2):383-387.

39. Zamorano P, Wigdorovitz A, Perez-Filgueira M, Carrillo C, Escribano JM, Sadir AM, Borca MV: A I0-amino-acid linear sequence of VPI of foot and mouth disease virus containing B- and T-cell epitopes induces protection in mice. Virology 1995, 2I 2(2):614-62I.

40. Zamorano PI, Wigdorovitz A, Perez Filgueira DM, Escribano JM, Sadir $A M$, Borca MV: Induction of anti foot and mouth disease virus $T$ and $B$ cell responses in cattle immunized with a peptide representing ten amino acids of VPI. Vaccine 1998, 16(6):558-563.

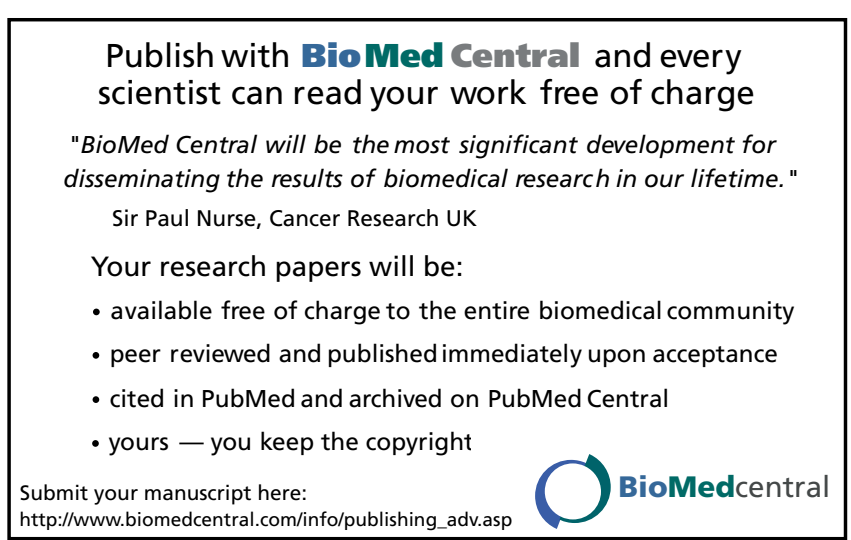

